than in the other, will produce anæsthesia in both sides of the body, but in a greater degree in the side opposite to that side of the cord where the lesion is most extensive.

Reading by the light of this conclusion the cases $I$ have reported in the preceding lecture, it will be seen that in Cases 1, 2, 4, 5, 11, 12, and 13 (see The Lancet, November and December, 1868), there was a lesion, almost entirely limited to one-half of the spinal cord, in its cervical region. On the contrary, there was a lesion extending to both sides in Cases $3,6,7,8,9$, and 10

3rd. A lesion in one side of the spinal cord produces a paralysis of the muscular sense in the corresponding, and not in the opposite, side.-We are not much advanced yet, as regards the physiological and pathological history of the muscular sense. We do know, however, that the conductors serving to give us an accurate notion of the state of contraction of our muscles are absolutely distinct from the conductors which give us the variety of painful sensations we may receive from these contractile organs. We know, also, that in cases in which an autopsy has been made, and the spinal cord found injured or diseased in one of its lateral halves, there was no alteration of the muscular sense in the parts that were not paralysed; and as the paralysis was on the side of the lesion in the spinal marrow, it is clear that the conductors serving to the muscular sense do not decussate in that nervous centre, or, in other words, that they remain, up to the brain, in the same side of the cord to which belong the muscles from which they come.

There is, therefore, a radical difference between the conductors which serve to give the peculiar kinds of sensation that belong to the muscular sense and those nerve-fibres which serve for all other kinds of sensation arising either from museles or from joints, from the skin, or from other parts of the trunk and limbs. The conductors serving for the muscular sense behave just like the voluntary motor conductors, and seem to follow exactly the same course in the spinal marrow. These two sets of conductors, I repeat, do not decussate in that organ; while, on the contrary, the conductors of impressions of tickling, of touch, of pain, and of temperature, all decussate before reaching the base of the brain.

I can conclude, therefore, that in the cases I have related in which the muscular sense was lost or diminished, in one side of the body (Cases 1, 2, 3, 4, and 7, in The LAncer, Nov. and Dec. 1868), there was a lesion in the corresponding side of the spinal cord.

\section{SCIENTIFIC INVESTIGATION INTO THE CAUSES OF CHOLERA.}

\section{A REPORT OF INTERVIEWS WITH PROF. MAX VON PETTENKOFER AT MUNICH, NOv. 1868.}

\section{Dr. D. DOUGLAS CUNNINGHAM}

DR. TIMOTHY LEWIS.

[THIs and the two subsequent reports on interviews with Professors De Bary and Hallier were kindly placed at our disposal by the Director-General of the Army Medical Department. The writers, Dr. Cunningham, of the Indian Medical Service, and Dr. Lewis, of the British Medical Service, having passed through the Army Medical School with great distinction, were selected by the Senate of the School for special service in India, in connexion with a thorough investigation of cholera which has been lately ordered by the Government. Before proceeding to India it was thought desirable that they should receive special instruction on the methods of investigating the forms of fungi, (as so much importance has been attached to this point,) and they were accordingly directed to go to Halle and Jena to see Professors De Bary and Hallier. Subsequently they proceeded to Munich to talk over the best methods of investigating cholera with Professor Von Pettenkofer. On returning home they presented short reports of their interviews, which, as expressing the latest views on the subject of cholera and of the fungoid theory of these eminent German Professors, will doubtless be interesting to our readers. We publish the Report on the interviews with Professor Pettenkofer this week, and those with Professors De Bary and Hallier shall follow. The Director-General informs ns that nothing could exceed the interest the German Professors took in the inquiry, and they showed the greatest kindness in discussing the subject with the two gentlemen. The same may be said also of the Rev. Mr. Berkeley, Mr. Huxley, Mr. Simon, Dr. Thomas Thomson, Dr. Burdon-Sanderson, and others in this country, who all most kindly gave Drs. Cunningham and Lewis the benefit of their suggestions.ED. L.]

During our stay at Munich Professor Pettenkofer went over the subject of cholera with great care, and at the close of our interviews with him made the following statements as a summary of his views:-

In my opinion four conditions (momente) are essential in order to bring about an epidemic of cholera:-
1. A specific germ.
2. Certain local conditions.
3. Certain seasonal conditions.
4. Certain individual conditions.

I have not investigated the nature of the cholera germ as disseminated by human intercourse. I have only taken for granted that it exists in the intestinal discharges of persons coming from infected places. (Vide "Untersuchungen über die Verbreitungsart der Cholera," Munchen, 1850.) My own investigations have been chiefly confined to the second and third before-mentioned conditions. Hitherto I have considered the human subject only so far as he is the bearer of the infecting matter of cholera, or of the germ of this matter; and have with facts contended against the pure contagionists, who declare that the infecting matter is produced by a process of multiplication within the bodies of those affected by the disease. My chief proofs of this have always lain in simple facts (independent of any theory) as to the spread of cholera over large districts. (See, for example, maps No. 8 and 11 in the Bavarian Cholera Report.) There are certainly places enjoying complete immurity from cholera, also periods of immunity. (Refer to my article on the Immunity of Lyons from Cholera, and the occurrence of Cholera on board ships, "Zeitschrift für Biologie," Bd. iv., pp. 400-4i14.)

The development of epidemics, and the immunity of many places, is totally inexplicable by the simple assumption of contagion from person to person. Observe the spread of epidemics along the course of railways and other ways of intercommunication indicated in the above-named maps. Nor are they to be explained by certain individual disposition of person (food, drinks, domestic arrangements, age, position, \&c.); but the circumstances require, besides these, the existence of local and seasonal aiding causes, which have to be assumed.

Are these in immediate relation to the cholera germ itself, or to the individual disposition? Facts speak in favour of the first opinion only. 1. Persons from an unaffected place going to an affected one, are attacked quite as numerously and as soon as the persons who constantly reside in these places. 2. Cases are on record where a person from an infected district conveys (in a way not yet clearly ascertained) infecting matter into a place enjoying complete immunity from cholera; and there, by means of this limited amount of infecting matter, infects a few persons who themselves had never been subject to the local conditions of an infected place, and therefore could not have had their individual disposition altered by it. (See the article on Lyons, where the enigmatical example of cases of cholera in Stuttgart in connexion with the cholera in Munich are recorded, pp. 424 to 426 ; see also cases recorded of persons infected on board ship who had not been on land, p. 428.) Facts imperiously demand that we should consider that the "seasonal" and "local" conditions are intimately connected with the cholera germ, although they may in addition be in a condition to act on the individual predisposition also.

The infecting matter, in my opinion, is not a product of the human intestines, but of the soil. In so far as we consider the cholera germ of an organised nature, and capable of various degrees of development, it is possible-nay, very 
probable-that there may be various degrees of infection. The distinction between cholera "germ" and cholera "infecting matter" must be noted. The cholera germ stands in the same relation to the infecting matter as the seed does to the fully developed plant.

In order to carry out a rational investigation of the specific infecting matter an exact study of the local and geasonal conditions of cholera epidemics is absolutely necessary, for it is only thus that one can"find where and when this infecting matter is to be sought with any prospect of success. The differences in the local and seasonal occurrences of cholera are at present the only substantial grounds for inferring the existence of a specific cholera germ and infecting matter. Exact statistics of the local and seasonal movement of cholera are indispensable. (Vide the tables concerning Bavaria in the Bavarian Report, p. 50.)

Closer examinations of isolated cholera places disclose that even in these more limited areas as great differences exist in the local conditions (proportionately) as in entire countries atd provinces. (Examples of such are given in his article on Lyons, p. 464, and in Pfeiffer's article on Weimar in "Zeitsehrift für Biologio," part iii., p. 189.)

Whatever has hitherto been advanced against the view that the soil exercises an essential influence on the spread of cholera epidemics has proved untenable on closer examination; in illustration of which refer to pages 91 and 98 in the Bavarian Report on Kienberg, and to the remarks of Dr. Sutherland on the condition of the soil at Gibraltar and Malta in the Sanitary Reports.

The seasonal disposition to cholera consists, in my opinion, in a certain degree of humidity combined with warmth of the soil. Refer to the article on Lyons, pp. 465-468. Note the definition of "ground water" in pp. 468,469; also a description of the influence of the rain season in Calcutta, Bombay, and Agra, in pp. 469-477, as well as the remarks on the infiuence of the Rhone on that portion of Lyons which is situated on alluvium, p. 484 .

Here I may also allude to the evidence establishing the connexion which existed between the ground water and ileo-typhus in Munich. When the former was at its lowest level, the latter raged the most. (Vide article on the subject, with diagram.)

Individual predisposition consists, in my opinion, as a rule, in a proportionately excessive amount of water in the tissue of organs, and a deficiency of albumen. This subject is treated at length in the "Zeitschrift für Biologie," part ii., pp. 92-97.)

In illustrating these views, the Professor entered at some length into a demonstration as to the grounds on which they are founded. In doing this he showed practically the method of estimating the percentage of the porosity of gravel, clay, and solid stone. He also showed the methods which he employs in ascertaining the temperature of the soil, and the lerel of the ground water.

\section{ON}

\section{THE NUTRITIVE VALUE OF DIFFERENT SORTS OF FOOD.}

\section{BY BARON LIEBIG.}

IT has been said that if man could live on air and water, there would be an end at once of the notions master and servant, sovereign and subject, friend and foe, hatred and affection, virtue and vice, right and wrong, \&c., and that our political commonwealth, social and family life, our intercommunication, tracle, commerce, and inclustry, art and science,-in short, all that makes man what he is, would not be if he had not a stomach, and were not subjected to a natural law which obliges him daily to take a certain quantum of nourishment. It is therefore worth while to answer the question why in reality man eats and drinks, and what the substances are which, received in the body during a succession of years, have an influence on the duration of his life.

If eating had no other end but to satisfy appetite, one might perhaps believe that by persoverance the habit could be got rid of. But hunger is the inner almonisher that tells us there is something wanting within the borly, and that we must supply the deficiency. That wo grow thinnor from privation of food, that we are cold and our forces diminish, while on the other hand our weight and bodily powers are kept up, and even increased, by taking nourishment, are facts which everyone can observe in his own person. But what we do not comprehend is, that in spite of this renovation, our body does not remain as it was, hnt gradually dies away.

What we know of life does not lielp us to comprehend death, which still remains an inscrutable mystery. The animal body is a warm body, which emits warmtl continually, and the heat thus lost must continually be replaced. It is, moreover, like a machine which daily performs a certain amount of work. The heart, or the muscles of the heart, work on uninterruptedly to keep up the circulation of the blood; the muscles of the chest to keep going the respiratory organs; and those of the entrails to maintain the worm-like motion of the organs of digestion. These are daily performances with which our will has nothing to do, while the mastication of our food, the motion of our limbs in walking and runuing, or otherwise working with them, are all dependent on our volition. The animal body has often been compared to a locomotive, in which, by air, water, and fuel working together, warmath and force are generated. Indeed, air and water are necessary conditions for the generation of heat and strength in the animal body, and food therefore may in a sense be considered as fuel: it has, however, other purposes also.

We all know how rapidly wear and tear ruins an engine; and that to put it in repair materials and work are necessary. The iron or copper which has to be renewell will not be replaced by giving the machine more fuel, and therefore an exterior human power-the power of many workmen-must co-operate and must be consumed, to make up the deficiencies of the machine, and set all right again.

Food does not serve to generate warmth and force only, as is the case with the steam-engine, but also to form and to increase the quickened parts of the animal body, and to reproduce those which are worn out.

If we keep in view these different purposes which food serves, it will be easy for us to form a decided notion of the nutritive value of different sorts of food. Physiology teaches us that all animated and plastic parts of the body arise from the blood, and that the component part of blool, which becomes fluid when heated, and is called albumen, is the material which serves for their construction.

All the different sorts of food of man, as well as that of animals, contain, without exception, sulsstances which are identical, or nearly identical, with the albumen of blood. This constitutes an entire group of substances found in plants, partly in solution in the juices, partly deprosited in the seeds, and which are found in greatest quantity in the cereals. The name given them is albuminate. In the nutritive process, albumen of the blood is formed from them; they are also called constituent nutritive substances, because they furnish the material for the formation of all the plastic parts of the body. From other organic substances they are materially distinguished, having an abundance of nitrogen, and by containing a certain amount of sulphur. The cheesy substance (casein) of milk; syntonin, the principal component part of the muscles; albumen, or that part of vegetable and animal juices which is soluble in heat; gluten of the cereals; vegetable casein in peas, beans, and lentils (legumin), all belong to the group of albuminates.

The component parts of human food and of the fodder of animals which are free of nitrogen, such as fat, starch, sugar, sugar of milk, \&c., are applied in the vital process, principally - and in part exclusively - for the generation of warmth. They have been named respiratory substances, or warmth. generating substances. The food of men and animals contains, besides, a third class of nutritive substances, known as nutritive salts. These are the substances which remain in the form of ashes when the articles of food are burned: phosphoric acid, potash, lime, magnesia, iron, common salt, are their chief elements.

The albuminates and heat-giving substances are quite incapable of nourishing and of sustaining life if the nutritive salts are not present, and co-operating with them. Without the nutritive salts they do not give nourishment. The idea of a perfect sort of food must be associated with three conditions; it must contain a certain quantity of albuminates, and there must also be a certain proportion of heat-giving substances, and of nutritive salts. We may accordingly speak of meat, 